\title{
Prescribing pattern of statins for primary prevention of cardiovascular diseases in patients with type 2 diabetes: insights from Ethiopia
}

\author{
Gebre Teklemariam Demoz ${ }^{*}$ CD, Shishay Wahdey², Gebremicheal Gebreslassie Kasahun ${ }^{1}$, Kalay Hagazy ${ }^{1}$ \\ Daniel Gebrehawaria Kinfe ${ }^{3}$, Hagos Tasew ${ }^{4}$, Degena Bahrey ${ }^{4}$ and Yirga Legesse Niriayo ${ }^{5}$
}

\begin{abstract}
Objective: Although most clinical practice guidelines endorsed statin use in type 2 diabetes (T2D) patients for reducing cardiovascular diseases (CVD), little is known about statin utilization in case of Ethiopia. Hence, this study was aimed to evaluate prescribing pattern of statins for primary prevention of CVD in T2D patients. A retrospective study conducted in T2D patients with the age group of 40-75 years. Prescriptions were audited for details of statin use and dose intensity. Descriptive analysis was performed using SPSS version 22.0.

Results: We included a total of 323 study subjects. Of those, $55.7 \%$ study subjects were found to be received statin for their primary prevention of CVD. Commonly prescribed type of statins was simvastatin (37.2\%), atorvastatin (32.8\%) and rosuvastatin (15.6\%). Low, moderate and high intensive dose of statins were prescribed in 27.8\%, 46.1\%, and $26.1 \%$, respectively. Of those subjects received statin, $60.6 \%$ had on target cholesterol level. Overall, a significant percentage of subjects did not receive their recommended statin for primary prevention of CVD which is below the guidelines' recommendation. Therefore, adherence to guidelines may help to promote the use of statins for primary prevention of CVD in T2D and advance interventions to improve statin prescribing should be considered.
\end{abstract}

Keywords: Type 2 diabetes, Statin, Prescribing pattern, Primary prevention, Ethiopia

\section{Introduction}

Cardiovascular diseases (CVD) is the leading cause of morbidity and mortality in patients with T2D [1]. Patients with T2D historically have two or three times higher rate of CVD than adults without diabetes [2]. No doubt the benefits of statins in secondary prevention of CVD have been explicitly established [3-6]; increasing evidence supports the role of statins in primary prevention of CVD as well $[7,8]$. Patients with T2D between 40 and 75 years, Low Density Lipid (LDL) of $70-189 \mathrm{mg} / \mathrm{dL}$ and without coronary artery disease or stroke are ideal candidates to receive statin therapy as a primary prophylaxis [9]. Furthermore, reducing high blood cholesterol, a risk factor for CVD in people with and without a past

\footnotetext{
*Correspondence: gebretekl@gmail.com

1 School of Pharmacy, College of Health Sciences, Aksum University, PO.Box: 298, Aksum, Ethiopia

Full list of author information is available at the end of the article
}

history of CVD is an important goal of pharmacotherapy. Statins are the drugs of choice for cholesterol lowering and cardioprotection. Thus, statins use should be considered in all people with T2D over 40 years of age $[4,10]$.

According to American Diabetes Association (ADA) standards of care recommend moderate-intensity statins for all T2D patients between the age of 40 and 75 years as a primary prevention. This evidence is strong for those patients with the age group of 40-75 years, represented statin use showing benefit [11]. Moreover, the American College of Cardiology/American Heart Association (ACC/AHA) clinical practice guidelines also suggest that patients 40-75 years of age with T2D and an LDL-C level of $\geq 70 \mathrm{mg} / \mathrm{dL}$, moderate-intensity statins is required without calculating 10-year ASCVD risk [12]. Formal risk estimation is unnecessary in people with T2D; since they are all at high risk of CVDs; thus proper uses of statins decrease the risk of coronary heart disease (CHD) in patients with T2D and hyperlipidemia [13].

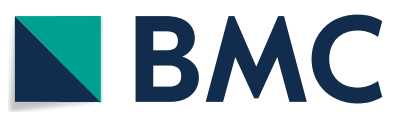

C The Author(s) 2019. This article is distributed under the terms of the Creative Commons Attribution 4.0 International License (http://creativecommons.org/licenses/by/4.0/), which permits unrestricted use, distribution, and reproduction in any medium, provided you give appropriate credit to the original author(s) and the source, provide a link to the Creative Commons license, and indicate if changes were made. The Creative Commons Public Domain Dedication waiver (http://creativecommons.org/ publicdomain/zero/1.0/) applies to the data made available in this article, unless otherwise stated. 
The benefits of statins use for primary prevention of CVD have been reported in numerous studies [14]. The Collaborative Atorvastatin Diabetes Study (CARDS), [15] reported a significant reduction in $\mathrm{CV}$ event rate in this specific population. Indeed, another meta-analysis shows that statins are effective agents that can reduce major coronary events by $21 \%$ and stroke by as much as $36 \%$ in diabetic patients [16].

Therefore, the rate of statin utilization increased progressively over the last 11-year period to an overall peak of $31.8 \%$ [17]. However, statically a low percentage of patients with T2D were prescribed a statin (35.1\%) [18]. One study conducted in United States large medical-care reported that $40 \%$ with diabetes had filled statin prescription [19]. Another interesting study was conducted in China indicated only $33.8 \%$ of patients with T2D received one or more lipid-lowering agents for the primary prevention of cardiovascular events [7]. In India statins were prescribed in $55.2 \%$ of patients with T2D [20]. In addition in Malaysia, $65 \%$ had a statin therapy prescription for primary prevention in T2D [21].

Although utmost contemporary clinical practice guidelines endorsed that statin use in those T2D patients with the age group between 40 and 75 years for reducing cardiovascular risks and all-cause mortality are proven significantly, underutilization of statins is reported in the sub-Saharan African countries [22, 23]. In Ethiopia, the escalating burden of CVD and its risk factors warrants for timely action and could be scaled up at a modest budget increase [24]. However, little is known about statin utilization in case of Ethiopia for primary prevention of CVD. Therefore, the primary purpose this study was aimed to evaluate the prescribing pattern of statins for primary prevention of CVD in T2D patients. This study may add to the previous scientific works by providing present-day data on the prescribing rates of statins for patients with $\mathrm{T} 2 \mathrm{D}$ in primary prevention of CVD.

\section{Main text \\ Methods \\ Study subjects and data collection procedures}

A 3 years retrospective study was conducted from July 2015 to June 2018. About 2360 outpatients' who were objectively diagnosed with diabetes chart were reviewed. Out of these, 323 subjects were included in the final analysis (Additional file 1). The study subjects were selected using systematic random sampling technique. The inclusion criteria were confirmed cases of T2D aged between 40 and 75 years, outpatients with T2D who had regular follow-up care of the clinic. Patients who had known history of myocardial infarction, acute coronary syndrome or stroke, angina, and patients with any other CHD were excluded from our study.
Data were collected from patients' medical chart which were included questions about sociodemographic and clinical details (includes diabetes complications, co morbidities, duration of diabetes, laboratory values and medication profiles). Here we evaluate whether statins should be used routinely for primary prevention of CVD in patients with T2D between the age of 40 and 75 irrespective of other risk factors.

Prescriptions were audited for different medications including statins, antidiabetic, and antihypertensive drugs. All types of prescribed statins were evaluated, while other forms of lipid-lowering agents (e.g., fibrates) were not included due to unavailability. We focused on the details of type of statin, up titration/equivalence dose and daily dose in mg/day. According to the $2017 \mathrm{ACC} /$ AHA guideline [12], statins were grouped into three levels of dose intensity based on their ability to lower LDL (low-intensity, moderate-intensity and high-intensity statins). (1) low intensity statins: atorvastatin $<10 \mathrm{mg} /$ day, rosuvastatin $<5 \mathrm{mg} /$ day, simvastatin $<20 \mathrm{mg} /$ day, and lovastatin $<40 \mathrm{mg} /$ day (2) moderate-intensity statins: $10 \mathrm{mg} /$ day $\leq$ atorvastatin $<40 \mathrm{mg} /$ day, $5 \mathrm{mg} /$ day $\leq$ rosuvastatin $<20 \mathrm{mg} /$ day, $20 \mathrm{mg} /$ day $\leq$ simvastatin $<80 \mathrm{mg} /$ day, lovastatin $\geq 40 \mathrm{mg} /$ day and (3) high-intensity statins: atorvastatin $\geq 40 \mathrm{mg} /$ day, rosuvastatin $\geq 20 \mathrm{mg} /$ day and simvastatin $\geq 80 \mathrm{mg} /$ day.

\section{Data analysis}

Data were entered and analyzed using EpiData Manager Version 4.0.2.00 (EpiData Association, Denmark) [25] and SPSS version 22.0 (SSPS Inc., Chicago, Illinois, USA), respectively. Demographics, clinical characteristics, and statin utilization were analysed and present categorical variables as percentages and continuous variables as means (standard deviations) or their $95 \%$ confidence intervals as appropriate.

\section{Results}

Socio-demographic and clinical characteristics

A total of 323 study subjects were included in this study. Nearly half $(51.4 \%)$ of the study subjects were females. More than half (58.2) of the study subjects were between 40 and 65 years of age. The mean diabetes duration since diagnosis of subjects were $(11.9 \pm 6.9)$ years. Detail baseline socio-demographic and clinical characteristics including laboratory parameters of the study subjects are summarized in Table 1.

Hypertension was present in $66.4 \%$, with a blood pressure $(\mathrm{BP})>140 / 90 \mathrm{mmHg}$ in $32.8 \%$ subjects. A total cholesterol $\geq 200 \mathrm{mg} / \mathrm{dL}$ in $27.2 \%, \mathrm{LDL} \geq 100 \mathrm{mg} / \mathrm{dL}$ in $62.2 \%$, triglycerides $\geq 150 \mathrm{mg} / \mathrm{dL}$ in $40.9 \%$, and HDL in $48.5 \%$. Of those subjects who received statin therapy, $60.6 \%$ of subjects were found to be on target cholesterol 
Table 1 Baseline demographic and clinical characteristics of patients with T2D in Ethiopia, 2018

\begin{tabular}{|c|c|c|c|c|c|}
\hline \multirow[t]{2}{*}{ Category } & \multirow[t]{2}{*}{ Subcategory } & \multicolumn{2}{|c|}{ Statin use $(\mathrm{N}=323)$} & \multirow[t]{2}{*}{ Total (\%) } & \multirow[t]{2}{*}{$P$ value } \\
\hline & & Not received & Received & & \\
\hline \multirow[t]{2}{*}{ Sex } & Male & $64(44.8)$ & $93(51.7)$ & $157(48.6)$ & 0.57 \\
\hline & Female & 79 (55.2) & $87(48.3)$ & $166(51.4)$ & \\
\hline \multirow[t]{2}{*}{ Age group } & $40-64$ & $86(60.1)$ & $102(56.7)$ & $188(58.2)$ & 0.33 \\
\hline & $65-75$ & $57(39.9)$ & $78(43.3)$ & $135(41.8)$ & \\
\hline $\mathrm{BMI}\left(\mathrm{kg} / \mathrm{m}^{2}\right)$ & Mean ( \pm SD) & $26 \pm 3$ & $26 \pm 3$ & $28.23 \pm 2.3$ & 0.161 \\
\hline Duration of diabetes & Mean ( $\pm \mathrm{SD})$ & $11.03 \pm 6$ & $13.12 \pm 7$ & $11.9 \pm 6.9$ & 0.051 \\
\hline \multirow[t]{2}{*}{ Presence of comorbidities } & Yes & $77(53.4)$ & $175(97.2)$ & $250(77.9)$ & 0.115 \\
\hline & No & $66(46.2)$ & $5(2.8)$ & $71(22.1)$ & \\
\hline \multirow[t]{4}{*}{ Types of co morbidities } & Hypertension & $60(72.3)$ & $112(63.6)$ & $172(66.4)$ & 0.169 \\
\hline & Dyslipidemia & $7(9)$ & $148(84.6)$ & $155(61.3)$ & 0.000 \\
\hline & $\mathrm{HD}$ & $3(3.8)$ & $30(17.0)$ & $33(13.0)$ & 0.004 \\
\hline & Others $^{\mathrm{a}}$ & $13(16.5)$ & $32(18.3)$ & $45(17.7)$ & 0.724 \\
\hline \multirow[t]{2}{*}{ Presence of complications } & Yes & $56(35.5)$ & $58(32.2)$ & $108(33.6)$ & 0.061 \\
\hline & No & $91(64.5)$ & $122(67.8)$ & $213(66.4)$ & \\
\hline \multirow[t]{3}{*}{ Types of complications } & Neuropathy & $42(75.0)$ & $40(61.5)$ & $82(67.8)$ & 0.114 \\
\hline & Nephropathy & $7(12.3)$ & $9(13.6)$ & $16(13)$ & 0.824 \\
\hline & Retinopathy & $8(14)$ & $17(25.4)$ & $25(20.2)$ & 0.117 \\
\hline $\mathrm{FBG}, \mathrm{mg} / \mathrm{dL}$ & Mean $( \pm S D)$ & $171.9 \pm 49.7$ & $178.1 \pm 48.1$ & $174.10 \pm 48.9$ & $<0.001$ \\
\hline$>130 \mathrm{mg} / \mathrm{dL}$ & & $41(28.6)$ & $59(32.8)$ & $241(74.6 \%)$ & 0.003 \\
\hline $\mathrm{LDL}, \mathrm{mg} / \mathrm{dL}$ & Mean $( \pm S D)$ & $109.1 \pm 33$ & $119 \pm 50$ & $115.7 \pm 35.6$ & 0.081 \\
\hline$\geq 100$ & & $181(74.2)$ & $41(36.3)$ & $222(62.2)$ & 0.058 \\
\hline $\mathrm{HDL}, \mathrm{mg} / \mathrm{dL}$ & Mean $( \pm S D)$ & $46 \pm 16$ & $44 \pm 16$ & $41.8 \pm 10.2$ & 0.624 \\
\hline$\leq 40$, male,$\leq 50$, female & & $121(49.6)$ & $52(46.0)$ & $173(48.5)$ & 0.712 \\
\hline Triglycerides, mg/dL & Mean $( \pm S D)$ & $159 \pm 62$ & $94 \pm 118$ & $158.2 \pm 121.2$ & 0.154 \\
\hline$\geq 150$ & & $113(46.3)$ & $33(29.2)$ & $146(40.9)$ & 0.081 \\
\hline Total cholesterol, mg/dL & Mean $( \pm S D)$ & $181 \pm 34$ & $193 \pm 54$ & $165.54 \pm 38.3$ & 0.067 \\
\hline$\geq 200 \mathrm{mg} / \mathrm{dL}$ & & $68(27.9)$ & $29(25.7)$ & $97(27.2)$ & 0.121 \\
\hline \multirow[t]{2}{*}{ Overall cholesterol level } & On target & $21(14.7)$ & $109(60.6)$ & $130(40.2)$ & \\
\hline & Not on target & $122(85.3)$ & $71(39.4)$ & $193(59.8)$ & 0.171 \\
\hline $\mathrm{eGFR}, \mathrm{mL} / \mathrm{min} / 1.73 \mathrm{~m}^{2}$ & $\leq 45$ & $31(12.7)$ & $13(11.50)$ & $44(12.3)$ & 0.221 \\
\hline \multirow[t]{2}{*}{$\mathrm{BP}(\mathrm{mmHg})$, mean $( \pm \mathrm{SD})$} & Systolic BP & $144.18 \pm 47.24$ & $139 \pm 20$ & $151.17 \pm 62.07$ & 0.415 \\
\hline & Diastolic BP & $84 \pm 14$ & $81 \pm 9$ & $85.11 \pm 0.08$ & 0.281 \\
\hline Systolic/diastolic & $>140 / 90$ & $98(40.2)$ & 19 (16.8) & $117(32.8)$ & 0.078 \\
\hline \multirow[t]{3}{*}{ Risk factors } & Low (T2D alone) & $141(98.6)$ & $93(51.7)$ & $234(72.5)$ & 0.031 \\
\hline & Medium (2-3) & $2(1.4)$ & $61(33.9)$ & $63(19.5)$ & 0.009 \\
\hline & $\operatorname{High}(\geq 4)$ & $0(0.0)$ & $26(14.4)$ & $26(8.0)$ & 0.002 \\
\hline
\end{tabular}

$B M I$ body mass index, $F B G$ fasting blood glucose, $L D L$ low-density lipoprotein, HDL high-density lipoprotein, eGFR estimated Glomerular Filtration Rate, $B P$ blood pressure, $S D$ standard deviation

a Thyroid disorders, peptic ulcer disease, asthmatic

level. Moreover, diabetic complications such as neuropathy, retinopathy and nephropathy with eGFR $\leq 45 \mathrm{~mL} /$ $\mathrm{min} / 1.73 \mathrm{~m}^{2}$ in $12.3 \%$, was seen in $67.8 \%, 20.2 \%$, and $13.0 \%$, respectively.

\section{Prescribed statins and other medication profiles}

Prescribed statins and others medications are shown in Table 2. Statins were prescribed in 180 (55.7\%) study subjects. The most frequently prescribed type of statin prescriptions was simvastatin (37.2\%), followed by atorvastatin $(32.8 \%)$ and rosuvastatin $(15.6 \%)$. Of those subjects received statins $(n=180)$, low-dose statins were prescribed in $27.8 \%$, moderate dose in $46.1 \%$, and high dose in $27.8 \%$. Likewise, high-dose statins were prescribed in the high risk (17.0\%), medium-risk (59.6\%), and low-risk (23.4\%) groups (Fig. 1). Furthermore, oral 
Table 2 Prescribing pattern of statins and other medications among patients with T2D in Ethiopia, 2018

\begin{tabular}{|c|c|c|c|}
\hline Variables & Subcategories & Frequency & Percent \\
\hline \multirow[t]{3}{*}{ Antidiabetic agents } & OGLD alone & 173 & 53.9 \\
\hline & Insulin alone & 57 & 17.8 \\
\hline & OGLD + insulin & 91 & 28.3 \\
\hline \multirow[t]{4}{*}{ Antihypertensive agents } & ACE inhibitors & 157 & 47.4 \\
\hline & Beta-blockers & 128 & 39.6 \\
\hline & Calcium channel blockers & 39 & 12.1 \\
\hline & Diuretics & 69 & 21.5 \\
\hline \multirow[t]{2}{*}{ Antiplatelets } & Aspirin & 35 & 10.8 \\
\hline & Clopidogrel & 5 & 1.5 \\
\hline Lipid lowering agents & Statins & 180 & 55.7 \\
\hline \multirow[t]{4}{*}{ Prescribed type of statins } & Simvastatin & 67 & 37.2 \\
\hline & Atorvastatin & 59 & 32.8 \\
\hline & Rosuvastatin & 28 & 15.6 \\
\hline & Lovastatin & 26 & 14.4 \\
\hline \multirow[t]{3}{*}{ Statins in various dose-intensity } & Low intensity & 50 & 27.8 \\
\hline & Moderate intensity & 83 & 46.1 \\
\hline & High intensity & 47 & 26.1 \\
\hline Source of medication $(n, \%)$ & For free & 188 & 58.2 \\
\hline
\end{tabular}

$A C E$ angiotensin converting enzyme, $T 2 D$ type 2 diabetes

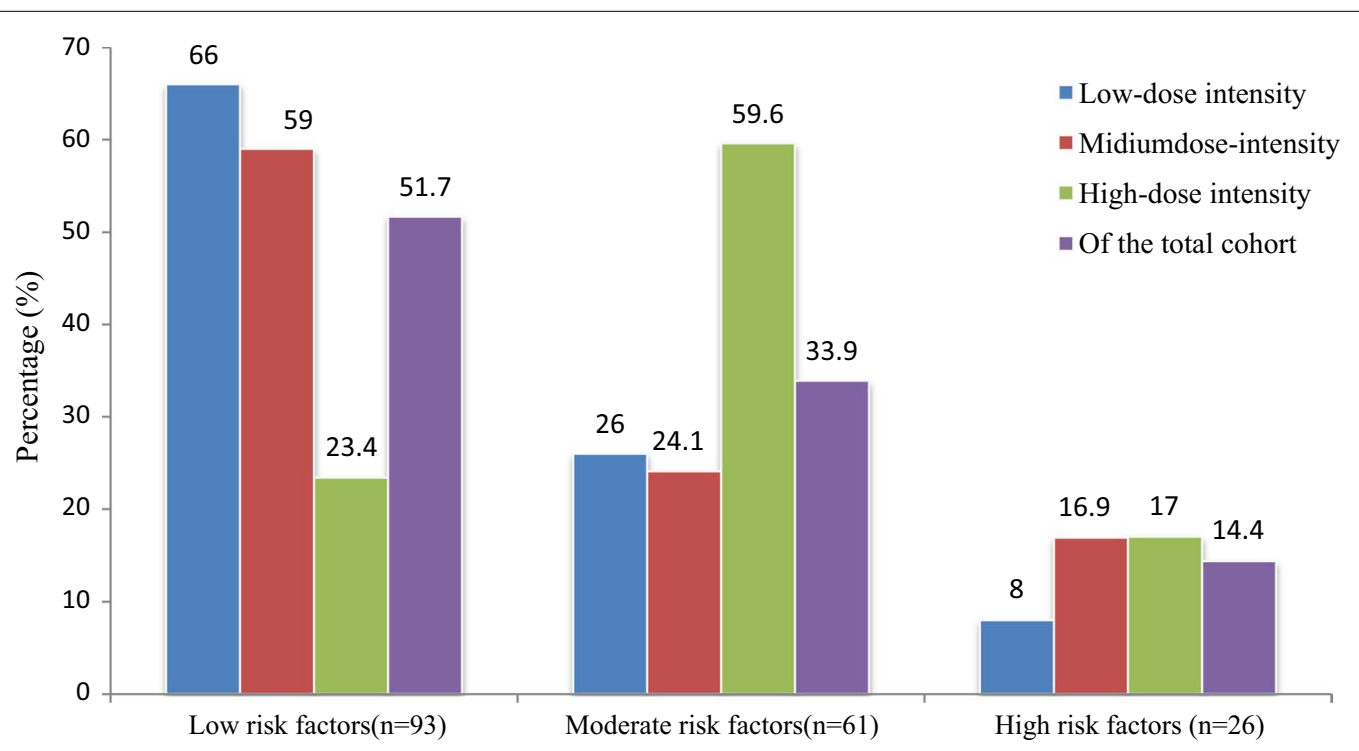

Fig. 1 Risk factors in relation to statin dose-intensity among patients with T2D, 2018

glucose lowering drugs alone and insulin alone was prescribed in $53.9 \%$ and $17.8 \%$, respectively.

\section{Discussion}

The current study sought to provide an up-to-date data on statin prescription utilization for the primary prevention of CVD in subjects with T2D who had no history of CVD in Ethiopia. We evaluated the prescription pattern for specific statin regimens in patients with T2D for primary prevention of CVD. In the present study, the prescription audit shows that statins are prescribed in 55.7\% (95\% CI 50.2-61.9) of patients with T2D. Simvastatin $(37.2 \%)$, atorvastatin $(32.8 \%)$ and rosuvastatin $(15.6 \%)$ are commonly prescribed types of statins. Moderate-dose of statins are prescribed in less than half $(46.1 \%)$ of the study subjects. 
The present result was consistent with the study reported from India, 55.2\% [20]. Whereas compared with findings reported from Malaysia, 65\% [21] for primary prevention of CVDs in hospitalized patients with T2D, our data show that lower rates of prescription use of statins. In addition, the prescribing pattern of statins for the primary prevention of CVD in patients with T2D of this study was higher than studies from Denmark, $47 \%$ [26], USA, 40\%, [19] and China, 33.8\% [7]. This discrepancy could be explained by the difference in number of risk factors in subjects involved in the study, study design and setting.

In our study more than half (58.2\%) of subjects in our study were obtained for free who had authorized by the responsible body. However, because of unavailability patients may went without the prescribed statin and stay until the next visit. In fact, in Africa and many of other middle income nations, patients with diabetes are suffering from unavailability and unaffordability of their drugs resulting to remain the leading barrier in diabetes care $[27,28]$. Therefore, this pronounced incidence of suboptimal statin utilization in our study may highlight a need for the prescribers and responsible body to pay more emphasize in prescribing statins to patients with T2D.

Although the prescriptions of statins are significantly greater in high-risk study subjects, the overall prescriptions of statins as well as high-dose statins are suboptimal and much lower than the standard guidelines' recommendations $[9,12]$. This is in contrary to the explicit benefit of statins use for the primary prevention of CVD in patients with T2D that contemporary standards of care guidelines recommend, moderate-dose intensity of statins for all T2DM patients between the age of 40 and 75 years $[9,11,12]$.

The implication of statins prescription use also supported by a large randomized controlled trial aimed to show the usefulness of statin for the primary prevention of CVD in subjects with T2D who had at least one or more of CVD risk factors, also showed a superior risk reduction of CVD events in 37\% of statin users [14]. Thus, it seems to suggest that some level of clinical inertia, where prescribers might be slow in responding to the clinical parameters. The prescribing practice of statins showed that there is a need to intensify statin use in compliance to the contemporary clinical guidelines' recommendations.

Furthermore, the present study indicates simvastatin was the most commonly prescribed type of statin, followed by atorvastatin and rosuvastatin. In contrary, finding reported from India [20] shows atorvastatin was the most commonly prescribed type of statin (74.1\%), followed by rosuvastatin (29.2\%). Unfortunately, moderate-dose of statins is recommended for all patients with T2D with the age of 40-75 years $[9,11,12]$. In our study we found that moderate dose intensity are prescribed in less than half (46.1\%) of the study subjects. Likewise, majority (65\%) of prescribed statins were maintained on the same dose with a very small number (8\%) had their dosages titrated upwards. In addition, only $6 \%$ of study subjects had switched with appropriate dose of equivalency.

Interestingly, the present study found that of those subjects who received statin therapy, only $60.6 \%$ of subjects were found to be on target cholesterol level. Certainly, only nearly two-fifth $(39.5 \%)$ of study subjects of this study had detailed lipid profile. This indicates noncompliance with the standard guidelines about monitoring of lipid profile that all patients with T2D should be tested at least annually [9]. This might also be the reason for: of those subjects who received statins, only $60.6 \%$ had on target cholesterol. Thus, need to emphasize periodic monitoring of their lipid in optimizing the utilization of statins in response to the CVD risks factors, indicating that statin prescription decisions are, at least in part, based on the risk assessment and lipid profile.

Another interesting finding of the present study, compared to subjects who did not receive statin, poor glycemic control had worsened in subjects who received statins (32.8\% versus $28.6 \%$ ). This could be explained due to the fact that simvastatin was the most commonly prescribed type of statin (37.2\%) in which simvastatin has the potential effect in reducing insulin secretion and sensitivity [29].

\section{Conclusions}

In conclusion, this study shows that prescriptions of statins in patients with T2D in Ethiopia are suboptimal indicating that utilization of statins among patients with T2D was substantially far below the current clinical guidelines' recommendation. Efforts in adherence of the contemporary clinical guidelines may help to promote the use of statin to all patients with T2D for primary prevention of CVD is urgently required.

\section{Limitations of the study}

This study was conducted at a single center that may have limitation in generalizability.

The inherent problems associated with being used retrospective study design may also another limitation that statin prescription utilization might depend on other factors not documented in the current registry. Thus, the retrospective nature of the study may limit the generalizability of the evidence that was generated from the study. 


\section{Additional file}

Additional file 1: Figure S1. Schematic flowchart of participant recruitment for analysis.

\section{Abbreviations}

ADA: American Diabetes Association; CVD: cardiovascular disease; eGFR: estimated Glomerular Filtration Rate; FBG: fasting blood glucose; IDF: International Diabetes Federation; LLAs: lipid-lowering agents; OGLD: oral glucoselowering drugs; SMBG: self-monitoring of blood glucose; WHO: World Health Organization.

\section{Acknowledgements}

Our gratitude goes to all staffs of the diabetes center for their dedicated work and valuable input.

\section{Authors' contributions}

GTD was made substantial contributions to the conception, design of the work, analysis, wrote the final manuscript, revised it critically and submitted it. YLN, HT, and $\mathrm{KH}$ had equally contributed to analysis and interpretation of the data. KH, HT and DB analyzed and interpreted the data, drafted the manuscript. GGK, SW and DGK have made substantial contribution in reviewing overall the study in analysis, data interpretation, and substantively revised the work. All authors read and approved the final manuscript.

\section{Funding}

Not applicable.

\section{Availability of data and materials}

Data that aid the findings of the current study are available from the corresponding author.

\section{Ethics approval and consent to participate}

Ethical approval and clearances was obtained from Institutional Review Board (IRB), Aksum University; and subsequent permission was obtained from the diabetes clinic of the hospital. The methods were carried out in accordance with the relevant guidelines and regulations of the IRB of the University.

\section{Consent for publication}

Not applicable.

\section{Competing interests}

The authors declare that they have no competing interests.

\section{Author details}

1 School of Pharmacy, College of Health Sciences, Aksum University, PO.Box: 298, Aksum, Ethiopia. ${ }^{2}$ School of Public Health, Mekelle University, Mekelle, Ethiopia. ${ }^{3}$ School of Medicine, Aksum University, Aksum, Ethiopia. ${ }^{4}$ Nursing School, Aksum University, Aksum, Ethiopia. ${ }^{5}$ School of Pharmacy, Mekelle University, Mekelle, Ethiopia.

Received: 14 May 2019 Accepted: 29 June 2019

Published online: 09 July 2019

\section{References}

1. King H, Aubert RE, Herman WH. Global burden of diabetes, 1995-2025: prevalence, numerical estimates, and projections. Diabetes Care. 1998;21:1414-31.

2. W.H. Organization. Global report on diabetes. Geneva: World Health Organization; 2016.

3. Massing MW, Foley KA, Sueta CA, Chowdhury M, Biggs DP, Alexander CM, Simpson RJ. Trends in lipid management among patients with coronary artery disease: has diabetes received the attention it deserves? Diabetes Care. 2003;26:991-7.

4. Naeem F, McKay G, Fisher M. Cardiovascular outcomes trials with statins in diabetes. Br J Diabetes. 2018;18:7-13.
5. Svensson E, Nielsen RB, Hasvold P, Aarskog P, Thomsen RW. Statin prescription patterns, adherence, and attainment of cholesterol treatment goals in routine clinical care: a Danish population-based study. Clin Epidemiol. 2015;7:213.

6. Tomkin $\mathrm{GH}$. Targets for intervention in dyslipidemia in diabetes. Diabetes Care. 2008;31:S241-8.

7. Lee VW, Ho IC, Chan WS, Tam KY, Lee KK. Statin utilization patterns for the primary prevention of cardiovascular events: a retrospective study in patients with diabetes mellitus in Hong Kong. Am J Cardiovasc Drugs. 2008;8:199-205.

8. Ramos R, Comas-Cufí M, Martí-Lluch R, Balló E, Ponjoan A, AlvesCabratosa L, Blanch J, Marrugat J, Elosua R, Grau M. Statins for primary prevention of cardiovascular events and mortality in old and very old adults with and without type 2 diabetes: retrospective cohort study. BMJ. 2018;362:k3359.

9. IDF, International Diabetes Federation. Clinical practice recommendations for managing type 2 diabetes in primary care. Brussels: IDF; 2017. ISBN: 978-972-930229-930285-930220.

10. Berthold HK, Gouni-Berthold I, Böhm M, Krone W, Bestehorn KP. Patterns and predictors of statin prescription in patients with type 2 diabetes. Cardiovasc Diabetol. 2009;8:25.

11. American Diabetes Association. Standards of medical care in diabetes-2019. ADA Diabetes Care J Clin Appl Res Educ. 2019;42(Suppl 1):S90-102. https://doi.org/10.2337/dc19-S009.

12. Whelton PK, Carey RM, Aronow WS, Casey DE, Collins KJ, Himmelfarb CD, DePalma SM, Gidding S, Jamerson KA, Jones DW. 2017 ACC/AHA/AAPA/ ABC/ACPM/AGS/APhA/ASH/ASPC/NMA/PCNA guideline for the prevention, detection, evaluation, and management of high blood pressure in adults: a report of the American College of Cardiology/American Heart Association Task Force on Clinical Practice Guidelines. J Am Coll Cardiol. 2018;71:e127-248.

13. Lin Y-C, Yang C-C, Chen Y-J, Peng W-C, Li C-Y, Hwu C-M. Utilization of statins and aspirin among patients with diabetes and hyperlipidemia: Taiwan, 1998-2006. J Chin Med Assoc. 2012;75:567-72.

14. Colhoun HM, Betteridge DJ, Durrington PN, Hitman GA, Neil HAW, Livingstone SJ, Thomason MJ, Mackness MI, Charlton-Menys V, Fuller JH. Primary prevention of cardiovascular disease with atorvastatin in type 2 diabetes in the Collaborative Atorvastatin Diabetes Study (CARDS): multicentre randomised placebo-controlled trial. Lancet. 2004;364:685-96.

15. Ginsberg HN. Efficacy and mechanisms of action of statins in the treatment of diabetic dyslipidemia. J Clin Endocrinol Metab. 2006;91:383-92.

16. Costa J, Borges M, David C, Carneiro AV. Efficacy of lipid lowering drug treatment for diabetic and non-diabetic patients: metaanalysis of randomised controlled trials. BMJ. 2006;332:1115-24.

17. Parikh S, Shrank WH, Mogun H, Choudhry NK. Statin utilization in nursing home patients after cardiac hospitalization. J Gen Intern Med. 2010:25:1293-9.

18. Pauff BR, Jiroutek MR, Holland MA, Sutton BS. Statin prescribing patterns: an analysis of data from patients with diabetes in the national hospital ambulatory medical care survey outpatient department and national ambulatory medical care survey databases, 2005-2010. Clin Ther. 2015;37:1329-39.

19. Steen Dylan L, Khan Irfan, Becker Laura, Foody JoAnne M, Gorcyca Katherine, Sanchez Robert J, Giugliano RP. Giugliano, patterns and predictors of lipid-lowering therapy in patients with atherosclerotic cardiovascular disease and/or diabetes mellitus in 2014: insights from a large US managed-care population. Clin Cardiol. 2014;40(2017):155-62.

20. Gupta R, Lodh S, Sharma KK, Sharma SK, Gupta S, Asirvatham AJ, Mahanta BN, Maheshwari A, Sharma DC, Meenawat AS, Khedar RS. Evaluation of statin prescriptions in type 2 diabetes: India Heart Watch-2. BMJ Open Diabetes Res Care. 2016;4:e000275.

21. Elnaem M, Nik Mohamed M, Huri H, Azarisman S. Patterns of statin therapy prescribing among hospitalized patients with type 2 diabetes mellitus in two Malaysian tertiary hospitals. Trop J Pharm Res. 2017;16:3005-11.

22. Elnaem MH, Mohamed MHN, Huri HZ, Azarisman SM, Elkalmi RM. Statin therapy prescribing for patients with type 2 diabetes mellitus: a review of current evidence and challenges. J Pharm Bioallied Sci. 2017;9:80.

23. Yebyo HG, Aschmann HE, Yu T, Puhan MA. Should statin guidelines consider patient preferences? Eliciting preferences of benefit and harm outcomes of statins for primary prevention of cardiovascular disease in 
the sub-Saharan African and European contexts. BMC Cardiovasc Disord. 2018;18:97.

24. Tolla MT, Norheim OF, Memirie ST, Abdisa SG, Ababulgu A, Jerene D, Bertram M, Strand K, Verguet S, Johansson KA. Prevention and treatment of cardiovascular disease in Ethiopia: a cost-effectiveness analysis. Cost Eff Resour Alloc. 2016;14:10.

25. EpiData Association 2000-20019. EpiData Software. http://www.epida ta.dk/index.htm. Accessed 21 Mar 2019.

26. Mortensen MB, Kulenovic I, Falk E. Statin use and cardiovascular risk factors in diabetic patients developing a first myocardial infarction. Cardiovasc Diabetol. 2016;15:81.

27. IDF, BLUE CIRCLE VOICES. Perspectives on barriers to access to diabetes care, medicines and supplies. Brussels: IDF; 2017.
28. IDF, International Diabetes Federation. Access to medicines and supplies for people with diabetes. Brussels: International Diabetes Federation; 2016.

29. Razali NR, Huri HZ, Ibrahim L, Vethakkan SR, Abdullah BM. Glycemic effects of simvastatin: where do we stand? Braz J Pharm Sci. 2018. https:// doi.org/10.1590/s2175-97902018000117192.

\section{Publisher's Note}

Springer Nature remains neutral with regard to jurisdictional claims in published maps and institutional affiliations.
Ready to submit your research? Choose BMC and benefit from:

- fast, convenient online submission

- thorough peer review by experienced researchers in your field

- rapid publication on acceptance

- support for research data, including large and complex data types

- gold Open Access which fosters wider collaboration and increased citations

- maximum visibility for your research: over 100M website views per year

At BMC, research is always in progress.

Learn more biomedcentral.com/submissions 